\title{
Regional Economic Conditions and the Variability of Rates of Return in Commercial Banking
}

\author{
Frederick Furlong and John Krainer*
}

Draft: September 2007

\begin{abstract}
We develop new techniques to assess the relationship between commercial bank performance and the economic conditions in the markets in which they operate. In the analysis, we allow for heterogeneity in the responses of banks to regional economic conditions. We find a statistically significant relationship between bank performance and shocks to the regional markets in which they operate. We find that region-specific shocks have a significant and persistent effect on the cross-sectional variance of bank performance in the market. That is, shocks affecting average performance of banks in a region also tend to increase the dispersion of their performance. We demonstrate that this effect is due to heterogeneity in the banks' exposures to their regional economies. Moreover, by allowing for this heterogeneity, we find that systematic responses to regional economic effects are notably more important in explaining the variation in bank performance than suggested by analysis in which responses are constrain to be the same for all banks.
\end{abstract}

* Both authors are from the Federal Reserve Bank of San Francisco. We thank seminar participants at the Federal Reserve Bank of Atlanta, Bill Keeton, and Jose Lopez for helpful discussions, and Irene Wang and Zena Knight for valuable research assistance. The views expressed in this paper are those of the authors and not necessarily those of the Federal Reserve System. 


\section{Regional Economic Conditions and the Variability of Rates of Return in Commercial Banking}

\section{Introduction}

Small banks, by virtue of their size and their emphasis on so-called relationship banking, tend to have limited geographic scope in their activities. This is especially true in connection with lending, with small banks tending to contract with pools of customers from limited geographic areas. The performance of a small commercial bank, then, is expected to be tied to the financial condition of its customers and, thus, to the economic conditions in the local banking market. ${ }^{1}$

Contrary to this expectation, studies testing for a relationship between bank performance and regional economic conditions find little evidence of systematic effects of economic conditions at the county level. Yeager (2004), for example, finds that performance of community banks in counties experiencing large economic shocks reflected in county unemployment rates was not much different from that of similar banks, but located in other counties. Using a different methodology, Emmons, Gilbert, and Yeager (2004) find that rates of return at community banks in the same region were not highly correlated in the late 1980s and early 1990s. Their results indicate that most of the potential reduction of diversifiable risk could be achieved though local market mergers rather than out-of-market mergers. They conclude that lack of scale, rather than exposure to local economic conditions, accounts for an important share of community banks’ exposure to diversifiable risk.

Studies that examine the influences of state level economic conditions find some support for regional economic effects on bank performance. Meyer and Yeager (2001) and Daly, Krainer, and Lopez (2007) find statistically significant effects of a variety of measures of state economic conditions on measures of bank performance. However, in the latter study, the model is not effective in predicting differences in problem loans for individual banks in out-sample simulations.

\footnotetext{
${ }^{1}$ Bank performance may also affect regional economic conditions. See Morgan, Rime, and Strahan (2002) for an analysis of how bank performance and integration affect regional economic growth.
} 
A feature of most previous approaches is an assumption that the systematic responses of bank performance measures to a change in economic conditions are the same for all community banks. However, specialization among community banks could lead to variation in business strategies and portfolio composition, which could, in turn, lead to variation in the systematic responses of performance to regional economic conditions. Also, most previous studies use measures of regional economic conditions such as employment growth or the unemployment rate. The studies in effect assume that the response of bank performance of a given change in the regional metric will be similar over time and across markets. However, it seems likely the responses of performance of banks to economic shocks driving a regional a metric could depend on the exact nature of the shock. If so, a systematic relationship between the performance of community banks and a measure of regional economic shocks may be difficult to detect.

In this study we present new empirical evidence based on analysis allowing for different systematic responses by individual banks to regional economic conditions. In the analysis, the region is the state. We also utilize measures of economic shocks related to aggregate bank performances. While the measures still do not identify the underlying sources of the shocks, they should reflect more reliably the relative magnitude of the shocks with respect to banks at different points in time and across regions.

The findings suggests that accounting for differences in the systematic response of individual banks to economic shocks is important for identifying the link between bank performance and regional economic conditions The responses of individual banks vary widely, ranging from significantly positive to significantly negative. The disparate responses of community banks also means that the state shocks tend to increase the crosssectional variance in performance among banks in a region. This latter result is additional evidence of regional effects on bank performance. It also is relevant to most studies assessing the average responses to economic shocks since the increase in variance would tend to reduce the precision of the estimated coefficients on the metrics for regional economic conditions. The analysis reveals a complicated picture of influences of economic conditions on community banks, one in which regional economic conditions have been extremely important for a number of community banks, of some influence for others, and of limited importance to the rest. 
The paper is organized as follows. Section 2 describes the approaches used in previous research assessing the relationship of bank performance to regional economic conditions. Section 3 develops the framework used in this study for assessing national, regional, and bank specific influences on rates of return for banks with identifiable geographic markets. The data used in the empirical analysis are described in Section 4. The empirical results regarding the effects of national and regional economic effects on the performance of community banks are presented in Section 5. Conclusions are presented in section 6.

\section{Previous approaches to assessing regional economic influences}

A common approach in the literature is to identify factors that proxy for overall economic conditions and correlate these factors with bank performance. In this tradition, researchers have used variables such as employment growth, unemployment rates, income growth, home price appreciation, and indexes based on several variables as measures of regional economic conditions. The scope of the market, or the region, is variously defined as the state, the metropolitan area, or the county. Most studies deal with smaller banks with regionally concentrated activities, as one is relatively confident about defining the market correctly for this set of institutions. One exception is Daly et al. (2007) which uses the geographic distribution of bank deposits to apportion regional economic influences for larger, interstate banking organizations. Measures of bank performance include rates of return on assets and equity, nonperforming assets, and charge offs. Some studies also include bank specific variables that are expected to influence bank performance such as loan composition.

With these variables in hand, the basic approach in most previous studies is to assess the effects of regional influences by regressing bank performance on one or more measures of regional economic conditions. It is common to include the lagged performance variable in the regressions. Most of these studies seek to measure the average effect of economic conditions on performance in a given region. An important assumption underlying this basic approach is that effects of the underlying economic factors, such as employment growth or real estate conditions, are similar for banks over 
time and across regions. Another important assumption is that banks in the same region are similar enough in their exposure to shocks that performance among banks will be positively correlated.

Using this approach, studies focusing on narrower geographic regions such as counties tend to find little correlation between measures of economic conditions bank performance (Meyer and Yeager (2001) and Yeager 2003). The findings suggest that variations in very local economic conditions are not an important source of risk for community banks. When state level data are used, studies find some evidence of systematic effects of economic conditions on banks (Nealy and Wheelock (1997), Meyer and Yeager (2001), and Daly et al. (2007).

Using a much different framework, Emmons et al. (2004) also argue regional or local market risk is not a major source of risk for community banks. Their study does not rely on measures of regional economic conditions such as unemployment. Rather the effects of regional conditions (local market risk) are assessed looking directly at the correlation structure of bank return on assets in a given market. The authors simulate hypothetical mergers to assess the potential effects on the reduction in risk among community banks, where risk reduction is derived from reducing variance of rates of return. The study finds that most of the risk reduction comes from in-market mergers, rather than out of market mergers.

Emmons et al. (2004) conclude that, for community banks, most of the potential diversification of risk could be achieved through increasing scale, rather than geographic diversification. The implication appears to be that exposure to local economic conditions is not a source of exposure to non-systematic (diversifiable) risk for community banks. However, in the assessing the effects of mergers on diversification, the study does not account for differences in business strategies (portfolio composition) among community banks in a region. Furlong (2004) shows that bank portfolio composition can vary considerably among community banks. Reductions in non-systematic risk in hypothetical random mergers of community banks in a region may be due more to increased portfolio diversification than to increased scale.

The previous studies provide valuable insights into relation of regional economic condition and average bank performance. For example, previous research suggests that, 
from a bank supervisory perspective, information about regional economic conditions may not provide useful forecasts of the likely performance of an individual bank. However, with a focus on the common or average effect of economic conditions on bank performance, the studies may understate the degree to which regional economic conditions affect the variability of the performance of individual banks because those banks have different systematic responses to region-wide shocks. Indeed, competition between banks may encourage them to specialize and find product niches (see Cohen and Mazzeo (2004)). This strategy would tend to loosen the correlation of performance across banks in a market in response to a particular kind of shock. To extent that this is the case, evidence on the common or average effects of regional economic conditions may not be a reliable guide to assessing the risk associated with limited geographic scope for the purposes of a assessing, say, appropriate, levels of regulatory capital.

\section{An alternative approach to modeling rates of return for banks}

The approach we take in assessing regional economic effects is to examine their impact on the variability of bank performance when allowing for the responses of individual banks to economic conditions, both nationally and regionally, to vary. We focus on rates of return (returns on assets and equity) as the measures bank performance. Under this approach we capture the effects of national and regional factors affecting the average bank performance by using measures of aggregate national and regional rates of return. The impact of regional shocks is assessed in two ways. The first is the degree to which individual bank performance is affected by the region-specific influences over time. Second, we measure the impact of regional shocks on the distribution of bank performance in the relevant region.

To develop the approach used in this paper, we start by noting that the performance of the average bank located in state $j$ can be apportioned between systematic (aggregate) banking sector risk and idiosyncratic state-specific risk.

$$
R_{j t}=\gamma_{j} R_{B t}+\varepsilon_{j t} .
$$


The systematic portion of performance, $\gamma_{j} R_{\mathrm{Bt}}$, owes itself to the fact that all banks are in the same basic business, and therefore share exposure to the same basic set of shocks to variables like interest rates and aggregate economic growth. This exposure is governed by $\gamma_{j}$. The term $\varepsilon_{j t}$ represents the idiosyncratic component of state $j$ 's banking performance The degree of idiosyncratic risk observed in the returns of banks in a specific state can be thought of as arising from the fact that not all state economies have the same industry mix, demographics, and contemporaneous rates of economic growth. A large, diversified state economy such as California may behave very similarly to the national economy as a whole. For smaller, less-diversified economies such as Alaska, state economic growth may look very different from the aggregate, and these differences would likely appear in the state-specific component of Alaska's banking sector performance.

Using the same logic as above, we model the performance of an individual bank $i$ operating in state $j$ as

$$
R_{i j t}=\theta_{i} R_{j t}+\eta_{i t} .
$$

The sensitivity to aggregate and state-specific factors affects individual bank $i$ 's performance through $R_{j t}$ and through its exposure to those risks, $\theta_{i}$. As before, the idiosyncratic term, $\eta_{i t}$, reflects the fact that individual banks are likely to have firmspecific components in their performance measures due to their unique circumstances, business strategy, and customers.

Combining (1) and (2) yields,

$$
R_{i j t}=\beta_{i} R_{B t}+\theta_{i} \varepsilon_{j t}+\eta_{i t} .
$$

Equation (3) is a starting point for empirical analysis. The coefficient $\beta_{i}$ represents the sensitivity of an individual bank's rate of return to the aggregate, national rate of return (for community banks). Note that the sensitivity of bank $i$ to aggregate shocks is given 
by, $\beta_{i}=\theta_{i} \gamma_{j}$. In other words, individual bank sensitivities reflect the average sensitivity to aggregate factors in that state, scaled by that bank's sensitivity to state factors. The term $\varepsilon_{j t}$ represents the regional conditions and their effect on banks, and $\theta_{i}$ measures the sensitivity of individual bank performance to regional conditions. The coefficients $\theta_{i}$ vary by bank, reflecting the potential for banks to differ according to their sensitivities to shocks of different kinds. Community banks tend to have business strategies directed at serving particular types of customers and providing certain types of services. Indeed, the limited size of a community bank may dictate a choice of specialization over diversification. As a result, in a given region, concentrations of consumer loans, business loans, and real estate loans can vary considerably among community banks. Note that by allowing for differences in responses to the national and regional conditions, some of what might be considered bank-specific effects related to say, portfolio differences, are

accounted for through the coefficients $\beta_{i}$ and $\theta_{i}$ in equation (3). Finally, the term $\eta_{i t}$ can be thought of as capturing the effects of other bank-specific factors. For example, banks will be exposed to the shocks that affect their individual customers, and these shocks may not be directly related to the national or the local economy. With limited scale, small banks will not be able to diversify away these risks, even though in expectation their effect is zero. Also, differences in management quality would affect individual bank performance given economic conditions and portfolio mix.

\section{The data}

The empirical analysis is based on a panel data set of small commercial banks. The data used in the empirical analysis are from the Reports of Condition (Call Reports) filed by all domestically chartered banks in the U.S. Because we are interested in assigning banks to a geographic region, we restrict our attention to small banks with assets less than $\$ 1$ billion.

In tables 1a and $1 \mathrm{~b}$ we report the number of small banks with usable Call Report data in our sample period. Not surprisingly, large states tend to have more small banks, on average. But also evident in table 1a is the legacy of the unit banking states such as 
Illinois and Texas, which tend to have far more small banks than similarly sized states (e.g., California). In the first quarter of 1984 there were 13,849 small banks (table 1b). By the fourth quarter of 2004 this number fell by 50 percent to 6,954. While most states experienced significant declines in the number of banks (the average decline over this period was 45\%), the Northeast experienced the biggest relative declines. Massachusetts lost $82 \%$ of its small banks during this 20 -year period. New Hampshire lost $83 \%$ of its small banks. The western states experienced less decline (or consolidation) in banking than average. Nevada experienced a doubling of the number of small banks headquartered there over this time period.

The aggregate U.S. bank rates of return are based on the performance of all community banks (assets less $\$ 1$ billion) with useable Call Report data in a quarter. The U.S. small bank performance over the sample period mirrors the same patterns observed in the industry as a whole. Average return on assets (ROA) and return on equity (ROE) over the 25 -year period were $0.8 \%$ and $9 \%$, respectively. In figures $1 \mathrm{a}$ and $1 \mathrm{~b}$ we see a fair amount of volatility in the aggregate (small bank) performance measures. Both measures recount the recent history in the banking sector, where bank financial condition suffered in the late 1980s during the banking crisis, but then recovered and has remained strong ever since. Note that the time-series of ROA and ROE associated with banks in the $25^{\text {th }}$ percentile are more volatile than the series for better-performing banks in the distribution. Evidently, a smooth series such as aggregate ROA masks a fair degree of heterogeneity in the cross-sectional distribution.

The aggregate regional data for bank rates of return are measured at the state level and, again, represent the weighted-average rates of returns for all small banks with useable Call Report data in the corresponding state in a given quarter. We focus on state level for this study because previous studies find some support for state economic effects on bank performance. By using states for the relevant regions, we can illustrate that even those findings of some systematic effects of regional economic tend to understate the impact of regional conditions on the variability of bank earnings. 


\section{Empirical finding regarding commercial bank exposures to national and regional shocks}

The first stage of the empirical analysis examines the sensitivities of regional performance to national factors. This exercise yields the state shocks which are then fed into the individual bank regressions of performance on both national and region-specific factors. Estimates of the relationships between state-level performances and aggregate performance are based on the full sample (described in the previous section). The individual bank regressions (equation (3) and its variants) are based on a balanced panel subset of the larger data set. The balanced panel contains observations on 5,255 different entities with continuous histories over the sample period. In these regressions we required each state to have at least 10 observations. The measures of bank performance are quarterly rates of return on assets (ROA) and rates of return on book-value equity (ROE). The data series for the aggregate rates of return and for individual banking organizations used for the balanced panel are seasonally adjusted.

\section{Estimates of region-specific conditions}

To derive the quarterly observation for the portion of the state level rates of return associated regional conditions, we estimate equation 3 (with a constant term) separately for each state. The results from state-by-state regressions are reported in tables 2a and 2b. The number of observations in each quarter varies among the states and over time. The time-series variation reflects both cyclical factors (entry and exit) as well as a declining trend in the number of banks due to consolidation.

The mean sensitivity of state ROA to aggregate (U.S.) ROA is 1.1 (1.2 for the case of ROE in table 2b). ${ }^{2}$ About four-fifths of the coefficients on aggregate ROA and ROE are significantly different from zero. Most, although not all, of the estimates are positive. Still there is a fair degree of dispersion in the estimates of state sensitivity to aggregate U.S. banking performance. For ROA, the $25^{\text {th }}$ percentile and the $75^{\text {th }}$ percentile of the distribution of estimates are 0.43 and 1.45 , respectively. For ROE, the $25^{\text {th }}$

\footnotetext{
${ }^{2}$ This average value for $\gamma$ across states contrasts with the weighted average $\gamma$ (by assets), which must sum to one by construction.
} 
percentile and the $75^{\text {th }}$ percentile of the distribution of estimates are 0.27 and 1.29, respectively. In general, the fit for the ROA regressions is better. The adjusted- $R^{2} \mathrm{~s}$ for the ROA regressions range from less than 1 percent (e.g., Rhode Island) to 90 percent (Colorado), with a median of about 50 percent, while the figures for the ROE regressions are less than 1 percent (Michigan) to 80 percent (Colorado), with a median of 18 percent.

The region-specific conditions (effects) for the states are the residuals from each of the regressions reported in tables $2 \mathrm{a}$ and $2 \mathrm{~b}$. Examples of the time series for the region-specific components of ROA and ROE are shown in figures $2 a$ and $2 b$ for three states-California, Oregon, and Arizona. The figures indicate that even for states in relatively close proximity, regional effects can differ substantially at any point in time. The pair-wise correlations for the state-specific components $\varepsilon_{\mathrm{jt}}$ in these three states never exceed 0.2. ${ }^{3}$

The state-specific conditions for these and other states tend to be serially correlated. This is not too surprising given the findings in previous studies that indicate significant serial correlation in the performance of individual banks. Studies such as Meyer and Yeager (2001) and Daly et al. (2007) find lagged performance measures are highly significant in regression of bank performance on regional conditions. ${ }^{4}$ The presence of serial correlation in the estimated $\varepsilon_{j}$ 's does raise the question of how reliable our standard errors are for the relevant coefficients.

\section{Individual bank exposure to regional condition}

The impact of economic conditions on the performance of community banks is assessed using the framework from equation (3) for each of the panel banks. Note that the estimation allows for variation in the responses of individual community banks to national influences and to region-specific effects. The analysis in this section is based on

\footnotetext{
${ }^{3}$ These low correlations at the state level point to the potential for diversification through inter-state banking.

${ }^{4}$ Previous studies generally have not used the estimates of the lagged adjustment to assess the long-run effects of regional conditions.
} 
a balanced panel of banks. We also only include the states for which the number of observations available to estimate the state shocks was 10 or more in every quarter. ${ }^{5}$

As noted above, the state-specific shocks are serially correlated. A possible approach, then, would be to address the serial correlation of the state-specific effects in estimating equation (1). Since our main interest is in the second-stage regressions and the coefficients on the state shocks and the remaining residual term, it may be inappropriate to purge the state shocks of serial correlation. It is entirely plausible that region-specific shocks have persistent effects on the banking sector. ${ }^{6}$ We would, however, like the residuals in the second stage regression to be white noise. Thus, we modify equation (3) as follows,

$$
R_{i j t}=\beta_{i} R_{B t}+\theta_{1, i} \varepsilon_{j t}+\theta_{2, i} \varepsilon_{j t-1}+\theta_{3, i} \varepsilon_{j t-2}+\theta_{4, i} \varepsilon_{j, t-3}+\eta_{i t} .
$$

The results from the estimation of equation (4) (with a constant term) relating to the distribution of the values of $\beta_{i}$ (the sensitivity to national condition) are shown in solid lines in figures 3a and 3b. As with the responses to the state levels of rates of return, the coefficients for community banks vary considerably. Overall, the coefficients tend to be positive; with about 70 percent of the sum of coefficients being positive for the ROA equations. The $25^{\text {th }}$ percentile and the $75^{\text {th }}$ percentile of the distribution of estimates are -0.2 and 1.3, respectively, with a median value of about 0.6 for the ROA equations (mean value of about .8). For ROE, the median and mean values for the coefficient on the national factor are about 0.6 and 1.1, respectively. ${ }^{7}$ A statistical test strongly supports the hypotheses that the means of the coefficients for U.S. ROA and ROE are not equal to zero.

The key parameters of interest in the model are the $\theta_{i}$, which measure the sensitivity of bank $i$ 's performance to economic conditions specific to the state. We

\footnotetext{
${ }^{5}$ This criterion eliminated Alaska, the District of Columbia, Hawaii, and Rhode Island.

${ }^{6}$ Berger et. al. (2000) document the persistence of bank performance.

${ }^{7}$ Yeager (2003) points out that that convergence of regional economies over time could affect the importance of regional effects on bank performance. At the state level, economies have tended to become more diversified.
} 
report statistics from the distribution of the sums of $\theta_{i}$ in dashed lines in figures $3 \mathrm{a}$ and 3b. From the figures, the median values of the sums of $\theta_{i}$ for the ROE and ROA regressions are approximately 0.5 (the mean values are about 0.6 and 0.7 , respectively). The statistical tests strongly support the hypotheses that the means of the coefficients for the state components of ROA and ROE are not equal to zero. Moreover, while we can not reject the hypotheses that the estimates are from a distributions with means greater than zero, the coefficient on the state components of ROA and ROE are negative and statistically significant for a minority of banks in the panel. Among the results from the individual bank regressions for ROA, about $40 \%$ of the sums of the coefficients on the state shocks are positive and significantly different from zero and another $10 \%$ are negative and statistically significant. The results for the ROE regressions are $42 \%$ positive and $12 \%$ negative and significant.

The results from statistical analysis also highlight the considerable variation in the systematic responses of the performance of individual banks to factors affecting banks nationally and in their respective states. The variation in the response to statespecific conditions also is somewhat larger than that for the responses to national conditions. For example, the inter-quartile range for the distribution of $\beta_{i}$ is 1.26 for ROA, compared to 1.5 for the sum of $\theta_{i}$ coefficients. It is also worth noting that the variation in the sums of $\theta_{i}$ is present not only among banks in different states, but also among banks in the same state.

The interpretation of the results is that state shocks can have a potentially large effect on individual bank performance. The size of this effect depends not only on the size of the shock, but also on the varying degree to which banks are positioned to be affected by the shock. Banks with large $\theta$ s have apparently selected strategies that, at least ex-post, made them more vulnerable to shocks typical in their regional (in this case state) markets. The wide variation in even the systematic responses of community banks to state shocks may be part of the reason that previous research has found regional economic conditions do little to improve out-of-sample forecasts of bank performance. Moreover, it also is possible that the range of systematic responses, significantly negative to significantly positive, found using state level data may also be indicative of community 
bank exposures at narrower geographic aggregations, such as counties and may mask the role of regional shocks when assessed by the average impact.

\section{Regional shocks and the cross-sectional distribution of community bank performance}

The variation in systematic response to state-specific (as well as national) economic conditions (i.e., shocks to those conditions) suggests that the effect of statespecific conditions should be assessed not just on the average effect on community bank performance, but also on the distribution of bank performance. The next steps in the empirical analysis are to assess the effect of state shocks on the variance of return for the individual community banks and the effects of state shocks to the distribution of rates of return in a given state

In examining the effects on the cross-sectional distributions of rates of returns among banks in the same state, we include ROA and ROE for all community banks with useable Call Reports in a given state and quarter. The approach is to examine how the value of a regional shock at a point in time affects the distribution of bank performance. The idea is that, if banks are affected differentially by regional shocks, then regional shocks should increase the dispersion of performance.

For this analysis, then, we compute the variance of the distribution of ROA and ROE for each state for each quarter over the sample period. The magnitude of regional

shocks is measured in two ways - the absolute value of shock, $\left|\varepsilon_{j t}\right|$, and the square of the shocks, $\left(\varepsilon_{j t}\right)^{2}$. The observations then are quarterly for each state. For each state, we first use pooled-cross sectional regressions where the dependent variable is variance of the rates of return (ROA or ROE) of all banks in a state at time $t$ and the explanatory variable is either the absolute value of the regional shock (or the square of the shock) at time $t$. We use pooled cross-section regressions for all the states with state-fixed effects.

The results for the regressions are shown in tables 3a and 3b. In the pooled crosssection the measures of the dispersion of bank performances are positively and significantly related to both metrics of the state-level shocks. As indicated, the regressions were estimated with and without controlling for state-specific and time period 
(quarterly) effects. ${ }^{8}$ The main result in this section is that the effects of the shocks on the variances of performance are positively correlated with variation in the sums of the coefficients $\theta_{i}$. This indicates that the effects of regional shock to banking are manifested in the distribution of bank performance within a state. To the extent that regional shocks tend to increase the variance of performance of banks in a region, this would tend to make it more difficult to reject the hypothesis that regional shocks do not affect bank performance when the test is on the effects on the level of ROA or ROE of banks. Evidently, regional economic conditions have a statistically significant effect on the variance of bank performance in a given market, even while the effect of economic conditions on average performance might be muted.

We continue the analysis by exploring the dynamic relationship between regional shocks and the distribution of bank performance. Towards this end, the basic relationship between shocks to a banking market and their effect on the distribution of performance in that market can be summarized using a vector autoregression (VAR). In this exercise we estimate a pooled VAR,

$$
Y_{j t}=\phi_{0}+\phi_{1} Y_{j t-1}+\phi_{2} Y_{j t-2}+\phi_{3} Y_{j t-3}+\phi_{4} Y_{j t-4}+v_{j t}
$$

where $Y_{j t}$ is a two-dimensional vector containing the variance of ROA (or ROE) in a given state $j$ at time $t$ and a measure of the state shock at time t: alternatively, $\left|\varepsilon_{j t}\right|$ or $\left(\varepsilon_{j t}\right)^{2}$ for each state $j$. The $2 \mathrm{x} 1$ vector $\mathrm{v}_{\mathrm{t}}$ is a white noise process uncorrelated with $Y_{t}$. The pooling refers to pooling across states, so that the coefficients in equation (6) should be interpreted as average effects. To avoid problems associated with survivorship bias, the results presented below are based on the full sample (i.e., not the balanced panel). ${ }^{9}$

\footnotetext{
${ }^{8}$ Binary (zero-one) dummies variables were included to control for time invariant factors for the states and state invariant factors for each quarter. In the tables, the robust standard errors are reported in parenthesis.

${ }^{9}$ We conducted the same exercise for the balanced panel and found the same qualitative results. However, the magnitude of the relationship between the variance of state-level rates of return and the state shock was smaller, as the survivor firms in the balanced panel exhibit less volatility over the sample period.
} 
Figures 4a and 4b plot a two standard deviation shock to $\left|\varepsilon_{j t}\right|$ for both ROA and ROE. In 4a, note that even a two standard deviation shock is quite small. This reflects the fact that ROA in general is both small and not that variable in the banking data. The figure shows, however, that the average effect of changes in the state shock has a significant effect on the cross sectional variance of ROA in the state. The effect is significant immediately at the one quarter lag, and is persistent and positive out to 12 quarters. The same basic patterns are even more evident in figure $4 \mathrm{~b}$, where we plot the impulse response of the variance of ROE to a shock to $\left|\varepsilon_{j t}\right|$. Indeed, the magnitude of the effect is much larger for the more volatile ROE. A one standard deviation shock to $\left|\varepsilon_{j t}\right|$ initially moves the average variance of state ROE by about 2 percentage points. To put this into perspective, the average variance of state ROE is about 3 percent over our sample period.

To quantify the relationships in figures $4 \mathrm{a}$ and $4 \mathrm{~b}$, we perform a variance decomposition of the VAR in equation (6). ${ }^{10}$ The results of this decomposition are in Tables 4a and 4b. Evidently, the state shock accounts for approximately 8 percent of the explained variation in the state ROA variance over the 12 quarter horizon, with own variance explaining the remainder. As before, the results are similar for ROE. The state shock accounts for about 10 percent of the explained variation in state ROE variance consistently over the 12 period horizon.

We also consider the effects of state shocks on the idiosyncratic variance of bank performance in a market using the VAR framework. By replacing $\operatorname{var}\left(\mathrm{R}_{\mathrm{j} t}\right)$ in the vector $\mathrm{Y}_{\mathrm{t}}$ (equation 6) with $\operatorname{var}\left(\eta_{\mathrm{j} t}\right)$ from equation (5), we can re-estimate the VAR and simulate the response of the variance of bank-specific risk in a market to a shock to economic conditions. ${ }^{11}$ The impulse responses are much smaller, and are generally insignificantly different from zero, after the initial period. However, the impulse responses after controlling for regional effects suggest that the changing nature of the shocks themselves have some impact on the distribution of bank performance in a state. To the extent that

\footnotetext{
${ }^{10}$ We use the Cholesky decomposition in this exercise.

${ }^{11}$ To be precise, $\operatorname{var}\left(\eta_{\mathrm{jt}}\right)$ is computed by estimating $\eta_{\mathrm{ijt}}$ for the balanced panel (equation 4 ), and taking the cross-sectional variance of $\eta_{\mathrm{it}}$ for all banks in market $j$. The time-series $\operatorname{var}\left(\eta_{\mathrm{jt}}\right)$ for each market $\mathrm{j}$ is then inserted into the VAR in equation 6.
} 
shocks differ in a particular market and over time, some of the variation at a particular point in time will be embedded in our residuals from the estimation of equation (4) for banks in the panel.

\section{Time series variance for individual banks}

The evidence so far indicates that regional shocks had statistically significant effects on the performance of about one-half the community banks in our sample. Moreover, the effects of state shocks are evident in the distribution of the performance of community banks. In the next steps we consider the extent to which taking into account differences in the sensitivity of individual banks reduces the measured variation in their rates of return over time. In particular, we compare the distribution of the adjusted $R^{2}$ statistics from the two models of rates of returns for individual banks. For the first set, $R^{2} \mathrm{~s}$ were derived for each bank in the panel from regressions of ROA and ROE on aggregate U.S. ROA and ROE. The second set of $R^{2} \mathrm{~s}$ is from the estimates of equation 4, which includes both the national and state-specific component of rates of return. The distributions of the $R^{2}$ s are shown in figures $5 \mathrm{a}$ and $5 \mathrm{~b}$. For the U.S. market factoronly model of ROA, the mean $R^{2}$-adjusted statistic for the 5,255 bank-regressions is $12 \%$. Including the state shocks as explanatory variables raises the mean $R^{2}$ to $22 \%$. For the ROE regressions, the comparable statistics are a mean $R^{2}$ s of $10 \%$ for the U.S. marketfactor only model and a mean $R^{2}$ s of $21 \%$ when the state shocks are included. Kolmogorov-Smirnov tests for equality between the distributions in $5 \mathrm{a}$ and $5 \mathrm{~b}$ easily reject the null hypothesis that the pairs of distributions are equal (in each case, with pvalue 0.0 ). Also of note is the prominent skew to the distributions. For some banks, adding state effects goes a long way towards accounting for the variation of its performance over time. ${ }^{12}$

\footnotetext{
12 Moreover, the analysis only captures systematic effects. The degree of the systematic relationship can depend on the extent and type of specialization of a bank and the nature of the economic shocks. For example, a state's shocks might hit different economic sectors—commercial real estate, aerospace, IT, subprime residential real estate loans - at different points in time. In that case, the performance of a community bank with a diversified loan portfolio might exhibit a high degree of systematic exposure to state shocks. In contrast, a highly specialized bank likely would exhibit a low degree of systematic exposure, even though the bank would be affected by economic conditions in its own sector of specialization. Those effects would be measured as idiosyncratic effects.
} 


\section{Comparison without controlling for individual bank responses.}

The analysis above allows for individual bank responses to aggregate U.S. and state-specific components of rates of return. To provide a comparison to approaches in which responses to shocks are constrained, we estimated a counterpart to equation (4) by pooling the data for the balanced panel and estimating the average effects of the national and state-specific factors. Controlling for bank fixed effects, the results for the ROA regression are:

$$
\begin{array}{rllll}
R_{i j t}=-0.0001+1.04 R_{B t}+0.28 \varepsilon_{j t}+0.08 \varepsilon_{j t-1}+0.11 \varepsilon_{j t-2}+0.07 \varepsilon_{j, t-3} & R^{2}=0.02 \\
(0.038) & (0.054) & (0.028) & (0.023) & (0.028)
\end{array}
$$

The results from the ROE regression yield:

$$
\begin{aligned}
& R_{i j t}=-0.006+1.17 R_{B t}+0.17 \varepsilon_{j t}+0.21 \varepsilon_{j t-1}+0.13 \varepsilon_{j t-2}+0.17 \varepsilon_{j, t-3} \quad R^{2}=0.02 \\
& \begin{array}{lllll}
(0.113) & (0.076) & (0.041) & (0.032) & (0.047)
\end{array}
\end{aligned}
$$

The coefficients from both regressions are all statistically significant. ${ }^{13}$ For the state-specific effects, the sum of the coefficients is not far from the mean value taken from the distributions in figures 3a and 3b. However, for this measure of the statespecific shock, $\varepsilon_{j t}$, regional conditions do not explain much of average bank performance when the bank responses are constrained to be the same for all banks. This is in sharp contrast to the earlier results where we allow heterogeneity in the responses to the national and state effects.

\section{Conclusion}

The connection between regional economic conditions and the performance of community banks is far from straightforward. From our analysis, regional economic shocks have had statistically significant effects on community banks in the sample. However, the magnitudes and even the direction of effects vary widely. Also, state shocks tend to increase the variation in the performance of community banks. This 
finding is additional evidence of regional effects on bank performance. It also is relevant to most studies assessing the average responses to economic shocks since the increase in variance would tend to reduce the precision of the estimated coefficients. This is illustrated by the comparison of the results from the bank-by-bank analysis, which allow for heterogeneous responses to state-specific shocks, and the pooled cross-section time series analysis, in which responses of individual banks' rates of return to the state effects are constrain to be the same for all banks.

These results suggest that community banks are exposed to greater regional risk than suggested by previous studies. At the same time, the analysis points to the difficulty of drawing inferences about the implications of regional economic shocks for individual community banks. There is the wide range of systematic responses of community. The systematic responses reflect the interaction of individual bank strategies and the makeup of the combination of shocks in a given state over the sample period. In addition, the performance of most community banks still appears to be related in large part to bankspecific factors. This suggests that, even accounting for a bank's specific exposure to systematic risk (national and regional effects), its risk management and general business practices, as well as its customer base, likely will be very important in accounting for the variability of its performance over time.

\footnotetext{
${ }^{13}$ Robust standard errors are reported in parentheses.
} 


\section{References}

Acharya, V., Hasan, I., and Saunders, A., 2002. "Should Banks Be Diversified? Evidence from Individual Bank Loan Portfolios.” BIS working paper.

Berger, A., Bonime, S., Covitz, D., and Hancock, D., 2000. "Why are Bank Profits so Persistent? The Roles of Product Market Competition, Informational Opacity, and Regional/Macroeconomic Shocks.” Journal of Banking and Finance, vol. 24 (July 2000), pp. 1203-35.

Cohen, A., and Mazzeo, M., 2004. "Market Structure and Competition Amongst Retail Depository Institutions.” Federal Reserve Board of Governors working paper.

Daly, M. C., Krainer, J., and Lopez, J., (2003), "Regional Economic Conditions and Aggregate Bank Performance.” Forthcoming in Research in Finance.

Emmons, W., Gilbert A., and Yeager T., (2004). "Risk Reduction at Small Community Banks: Is it Size of Geographic Diversification that Matters?” Journal of Financial Services Research 25 2/3, pp.

Furlong F. T., (2004). “Comment on Emmons, Gilbert, and Yeager” Journal of Financial Services Research 25 2/3, pp. 283-289.

Krainer, J., 2001. “Banking and the Business Cycle.” Federal Reserve Bank of San Francisco Economic Letter.

Meyers, A. P., and Yeager, T. J., (2001), “Are Small Rural Banks Vulnerable to Local Economic Downturns?” Federal Reserve Bank of St. Louis Review, 83, pp. 25-38.

Morgan, D., Rime, B., and Strahan, P., 2002. "Bank Integration and State Business Cycles.” Working paper.

Morgan, D., and Samolyk, K., 2003. "Geographic Diversification and Bank Performance.” Working paper.

Neely, M. and Wheelock, D. (1997) "Why Does Bank Performance Vary Across States?” Federal Reserve Bank of St. Louis Review 79, pp 27-40.

Yeager, T. J., (2004), "The Demise of Community Banks? Local Economic Shocks are not to Blame.” Journal of Banking and Finance 28, pp 2135-2153. 
Table 1a: Distribution of Small Banks in United States

\begin{tabular}{|c|c|c|c|c|c|c|c|c|c|}
\hline State & Mean & Min & Max & Std. Dev & State & Mean & Min & Max & Std. Dev \\
\hline $\mathrm{AL}$ & 190.5 & 140 & 268 & 36.6 & MT & 119.5 & 74 & 168 & 36.6 \\
\hline AK & 6.5 & 4 & 15 & 3.3 & $\mathrm{NE}$ & 346.8 & 246 & 450 & 61.5 \\
\hline $\mathrm{AZ}$ & 33.4 & 23 & 48 & 6.6 & NV & 16.3 & 11 & 25 & 3.9 \\
\hline $\mathrm{AR}$ & 226.4 & 152 & 257 & 36.4 & $\mathrm{NH}$ & 29.2 & 10 & 62 & 17.7 \\
\hline CA & 316.8 & 189 & 412 & 75.3 & NJ & 78.4 & 54 & 117 & 18.1 \\
\hline $\mathrm{CO}$ & 285.2 & 148 & 429 & 107.7 & NM & 69.7 & 44 & 93 & 18.2 \\
\hline CT & 37.2 & 20 & 63 & 13.5 & NY & 113.7 & 88 & 152 & 18.7 \\
\hline $\mathrm{DE}$ & 18.5 & 10 & 27 & 4.6 & NC & 58.6 & 44 & 70 & 6.5 \\
\hline DC & 9.5 & 3 & 16 & 4.1 & ND & 135.1 & 96 & 177 & 27.0 \\
\hline FL & 297.5 & 206 & 388 & 60.6 & $\mathrm{OH}$ & 233.4 & 157 & 318 & 45.3 \\
\hline GA & 351.9 & 298 & 398 & 30.4 & OK & 369.3 & 256 & 521 & 85.3 \\
\hline HI & 4.4 & 1 & 8 & 2.7 & OR & 43.0 & 27 & 72 & 10.8 \\
\hline ID & 17.9 & 13 & 24 & 3.0 & PA & 223.2 & 138 & 313 & 53.3 \\
\hline IL & 915.0 & 604 & 1226 & 218.1 & RI & 5.5 & 1 & 12 & 3.2 \\
\hline IN & 233.4 & 122 & 380 & 85.2 & SC & 71.4 & 64 & 79 & 3.8 \\
\hline IA & 506.8 & 390 & 627 & 76.5 & SD & 110.1 & 78 & 142 & 18.4 \\
\hline KS & 473.5 & 343 & 614 & 95.9 & $\mathrm{TN}$ & 228.9 & 177 & 300 & 34.7 \\
\hline $\mathrm{KY}$ & 279.3 & 203 & 330 & 44.5 & $\mathrm{TX}$ & 1075.2 & 604 & 1876 & 416.3 \\
\hline LA & 195.8 & 129 & 290 & 52.8 & UT & 34.6 & 26 & 56 & 8.5 \\
\hline $\mathrm{ME}$ & 17.1 & 13 & 26 & 3.7 & VT & 20.3 & 12 & 27 & 4.5 \\
\hline MD & 78.0 & 51 & 96 & 10.1 & VA & 148.4 & 110 & 178 & 17.6 \\
\hline MA & 55.4 & 22 & 121 & 28.7 & WA & 79.7 & 68 & 94 & 7.0 \\
\hline MI & 214.1 & 139 & 358 & 72.3 & WV & 136.4 & 61 & 224 & 57.7 \\
\hline $\mathrm{MN}$ & 568.0 & 447 & 733 & 94.2 & WI & 413.0 & 263 & 596 & 108.7 \\
\hline MS & 110.5 & 85 & 158 & 18.8 & WY & 65.6 & 40 & 112 & 24.7 \\
\hline MO & 472.3 & 329 & 705 & 112.4 & & & & & \\
\hline
\end{tabular}

*Data from the Reports of Condition. Small banks are defined to have assets less than \$1 billion. 
Table 1b: Evolution of Banking Sector by State

\begin{tabular}{cccccc} 
State & $\mathbf{1 9 8 4 . Q 1}$ & $\mathbf{2 0 0 4 . Q 4}$ & State & $\mathbf{1 9 8 4 . Q 1}$ & $\mathbf{2 0 0 4 . Q 4}$ \\
\hline AL & 268 & 144 & MT & 165 & 76 \\
AK & 13 & 4 & NE & 448 & 246 \\
AZ & 35 & 39 & NV & 11 & 22 \\
AR & 252 & 156 & NH & 60 & 10 \\
CA & 383 & 190 & NJ & 117 & 58 \\
CO & 391 & 148 & NM & 93 & 45 \\
CT & 43 & 21 & NY & 152 & 92 \\
DE & 22 & 10 & NC & 58 & 59 \\
DC & 11 & 5 & ND & 176 & 96 \\
FL & 388 & 225 & OH & 318 & 157 \\
GA & 385 & 306 & OK & 506 & 256 \\
HI & 8 & 1 & OR & 72 & 30 \\
ID & 24 & 14 & PA & 312 & 141 \\
IL & 1226 & 604 & RI & 11 & 2 \\
IN & 380 & 122 & SC & 68 & 70 \\
IA & 627 & 390 & SD & 140 & 79 \\
KS & 608 & 347 & TN & 300 & 177 \\
KY & 329 & 203 & TX & 1698 & 604 \\
LA & 283 & 129 & UT & 56 & 30 \\
ME & 26 & 13 & VT & 27 & 12 \\
MD & 82 & 53 & VA & 178 & 111 \\
MA & 121 & 22 & WA & 92 & 69 \\
MI & 358 & 139 & WV & 224 & 61 \\
MN & 733 & 447 & WI & 596 & 263 \\
MS & 158 & 87 & WY & 112 & 40 \\
MO & 705 & 329 & & &
\end{tabular}


Table 2a: Regressions of State ROA on Aggregate ROA

$\mathrm{ROA}_{\mathrm{jt}}=\alpha_{\mathrm{j}}+\delta_{\mathrm{j}} \mathrm{ROA}_{\mathrm{Bt}}+\varepsilon_{\mathrm{jt}}$ where ROA $\mathrm{Bt}_{\mathrm{Bt}}$ is the aggregate bank ROA.

$\begin{array}{lc}\text { Mean } \delta & 1.1 \\ \text { Min } \delta & -0.5 \\ \text { Max } \delta & 4.3 \\ \text { \% signficant } & 96.1 \%\end{array}$

\begin{tabular}{cccccccc} 
State & $\boldsymbol{\delta}$ & $\mathbf{t}(\boldsymbol{\delta})$ & $\boldsymbol{R}^{\mathbf{2}}$ & State & $\boldsymbol{\delta}$ & $\mathbf{t}(\boldsymbol{\delta})$ & $\boldsymbol{R}^{\mathbf{2}}$ \\
\hline AL & 0.22 & 3.45 & $12.7 \%$ & MT & 2.05 & 14.99 & $73.3 \%$ \\
AK & 2.00 & 6.72 & $35.5 \%$ & NE & 0.94 & 9.37 & $51.7 \%$ \\
AZ & 4.26 & 13.50 & $69.0 \%$ & NV & 1.37 & 6.71 & $35.5 \%$ \\
AR & 0.73 & 9.75 & $53.7 \%$ & NH & 1.25 & 3.10 & $10.5 \%$ \\
CA & 0.72 & 4.56 & $20.2 \%$ & NJ & 0.48 & 3.10 & $10.5 \%$ \\
CO & 2.40 & 27.89 & $90.5 \%$ & NM & 1.71 & 21.09 & $84.4 \%$ \\
CT & 1.07 & 3.40 & $12.4 \%$ & NY & 0.06 & 0.74 & $0.7 \%$ \\
DE & 1.22 & 4.27 & $18.2 \%$ & NC & 0.22 & 2.55 & $7.3 \%$ \\
DC & 1.66 & 4.89 & $22.6 \%$ & ND & 1.14 & 14.69 & $72.5 \%$ \\
FL & 0.65 & 10.04 & $55.2 \%$ & OH & 0.52 & 10.71 & $58.3 \%$ \\
GA & 0.33 & 3.67 & $14.1 \%$ & OK & 1.92 & 17.22 & $78.3 \%$ \\
HI & -0.48 & -2.74 & $8.4 \%$ & OR & 1.91 & 13.96 & $70.4 \%$ \\
ID & 1.54 & 7.87 & $43.0 \%$ & PA & 0.26 & 4.56 & $20.3 \%$ \\
IL & 0.26 & 6.80 & $36.1 \%$ & RI & 0.21 & 0.44 & $0.2 \%$ \\
IN & 0.61 & 11.90 & $63.3 \%$ & SC & 0.56 & 6.59 & $34.6 \%$ \\
IA & 1.12 & 10.04 & $55.1 \%$ & SD & 0.95 & 7.93 & $43.4 \%$ \\
KS & 0.95 & 16.28 & $76.4 \%$ & TN & 0.53 & 8.07 & $44.3 \%$ \\
KY & 0.55 & 13.67 & $69.5 \%$ & TX & 2.44 & 17.79 & $79.4 \%$ \\
LA & 2.56 & 19.26 & $81.9 \%$ & UT & 3.05 & 21.90 & $85.4 \%$ \\
ME & 0.35 & 2.79 & $8.7 \%$ & VT & 0.72 & 3.31 & $11.8 \%$ \\
MD & 0.67 & 9.49 & $52.3 \%$ & VA & 0.36 & 4.22 & $17.8 \%$ \\
MA & 1.15 & 3.73 & $14.5 \%$ & WA & 1.09 & 16.97 & $77.8 \%$ \\
MI & 0.50 & 9.73 & $53.6 \%$ & WV & 0.19 & 2.18 & $5.5 \%$ \\
MN & 1.18 & 16.51 & $76.9 \%$ & WI & 0.58 & 12.88 & $66.9 \%$ \\
MS & 0.85 & 13.12 & $67.7 \%$ & WY & 2.44 & 14.01 & $70.5 \%$ \\
MO & 0.77 & 21.86 & $85.3 \%$ & & & & \\
& & & & & & &
\end{tabular}


Table 2b: Regressions of State ROE on Aggregate ROE

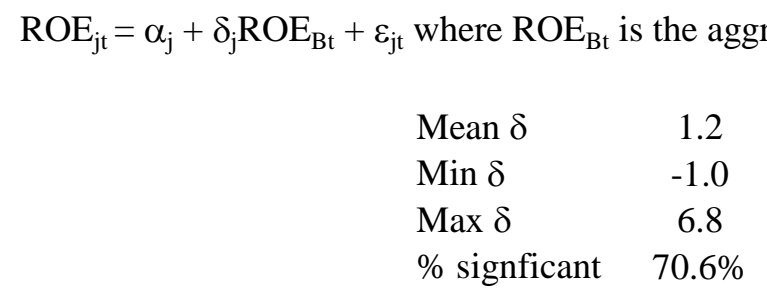

\begin{tabular}{cccccccc} 
State & $\boldsymbol{\delta}$ & $\mathbf{t}(\boldsymbol{\delta})$ & $\boldsymbol{R}^{\mathbf{2}}$ & State & $\boldsymbol{\delta}$ & $\mathbf{t}(\boldsymbol{\delta})$ & $\boldsymbol{R}^{\mathbf{2}}$ \\
\hline AL & 0.25 & 2.53 & $7.2 \%$ & MT & 2.52 & 10.35 & $56.6 \%$ \\
AK & 4.40 & 4.67 & $21.0 \%$ & NE & 1.01 & 6.50 & $34.0 \%$ \\
AZ & 6.84 & 8.80 & $48.6 \%$ & NV & 1.53 & 3.82 & $15.1 \%$ \\
AR & 0.69 & 5.85 & $29.5 \%$ & NH & 1.57 & 1.84 & $4.0 \%$ \\
CA & 0.13 & 0.51 & $0.3 \%$ & NJ & -0.17 & -0.57 & $0.4 \%$ \\
CO & 3.66 & 19.19 & $81.8 \%$ & NM & 2.01 & 12.11 & $64.1 \%$ \\
CT & 1.31 & 2.25 & $5.8 \%$ & NY & -0.30 & -1.79 & $3.7 \%$ \\
DE & 0.78 & 2.14 & $5.3 \%$ & NC & 0.16 & 1.05 & $1.3 \%$ \\
DC & 2.14 & 3.82 & $15.1 \%$ & ND & 1.35 & 10.37 & $56.8 \%$ \\
FL & 0.58 & 4.26 & $18.1 \%$ & OH & 0.36 & 4.05 & $16.7 \%$ \\
GA & 0.24 & 1.46 & $2.5 \%$ & OK & 2.35 & 11.79 & $62.9 \%$ \\
HI & -1.03 & -2.86 & $9.1 \%$ & OR & 1.77 & 7.41 & $40.1 \%$ \\
ID & 1.18 & 3.07 & $10.3 \%$ & PA & -0.11 & -1.15 & $1.6 \%$ \\
IL & -0.07 & -0.96 & $1.1 \%$ & RI & 1.01 & 1.50 & $2.7 \%$ \\
IN & 0.50 & 5.98 & $30.4 \%$ & SC & 0.47 & 3.43 & $12.5 \%$ \\
IA & 1.16 & 6.49 & $33.9 \%$ & SD & 0.77 & 4.48 & $19.6 \%$ \\
KS & 0.74 & 7.81 & $42.7 \%$ & TN & 0.37 & 3.06 & $10.2 \%$ \\
KY & 0.60 & 10.99 & $59.5 \%$ & TX & 3.51 & 13.33 & $68.4 \%$ \\
LA & 3.45 & 14.27 & $71.3 \%$ & UT & 3.25 & 13.89 & $70.2 \%$ \\
ME & -0.45 & -1.85 & $4.0 \%$ & VT & 0.31 & 0.78 & $0.7 \%$ \\
MD & 0.51 & 4.83 & $22.1 \%$ & VA & 0.18 & 1.26 & $1.9 \%$ \\
MA & 1.07 & 1.58 & $3.0 \%$ & WA & 0.96 & 8.40 & $46.2 \%$ \\
MI & -0.03 & -0.26 & $0.1 \%$ & WV & 0.12 & 0.96 & $1.1 \%$ \\
MN & 1.04 & 9.05 & $50.0 \%$ & WI & 0.38 & 5.96 & $30.3 \%$ \\
MS & 0.73 & 6.73 & $35.6 \%$ & WY & 3.10 & 9.25 & $51.1 \%$ \\
MO & 0.69 & 11.53 & $61.9 \%$ & & & &
\end{tabular}




\section{Table 3a: Pooled Time Series regression of variance of ROA of banks in a state on the shock to the distribution to bank ROA\#

$$
\operatorname{Var}\left(\mathrm{ROA}_{\mathrm{jt}}\right)=\mathrm{a}+\mathrm{b}\left(\text { shock }_{\mathrm{jt}}\right)
$$

Without controls With controls Without control With controls (state \& time)

\begin{tabular}{|c|c|c|c|c|}
\hline Intercept & $\begin{array}{l}1.266 \mathrm{e}-4 \\
(3.18 \mathrm{e}-6)^{* *}\end{array}$ & $\begin{array}{c}5.18 \mathrm{e}-5 \\
(1.42 \mathrm{e}-5)^{* *}\end{array}$ & $\begin{array}{l}8.866 e-5 \\
(3.53 e-6)^{* *}\end{array}$ & $\begin{array}{l}6.04 \mathrm{e}-5 \\
(1.53 \mathrm{e}-5)^{* *}\end{array}$ \\
\hline $\begin{array}{l}\text { Square of state shock } \\
\sum\left(\varepsilon_{\mathrm{jt}}\right)^{2}\end{array}$ & $\begin{array}{l}1.69 \\
(0.365)^{* *}\end{array}$ & $\begin{array}{l}1.177 \\
(0.241)^{* *}\end{array}$ & & \\
\hline $\begin{array}{l}\text { Absolute value of state } \\
\operatorname{shock}^{\# \#} \sum\left(\mathrm{abs}\left(\varepsilon_{\mathrm{j} t}\right)\right)\end{array}$ & & & $\begin{array}{l}0.032 \\
(0.002)^{* *}\end{array}$ & $\begin{array}{c}2.026 \mathrm{e}-2 \\
(2.647 \mathrm{e}-3)^{* *}\end{array}$ \\
\hline $\begin{array}{l}\mathrm{R}^{2} \\
\text { N } 3948\end{array}$ & 0.115 & 0.532 & 0.165 & 0.527 \\
\hline $\begin{array}{l}\text { significant at the } 1 \text { perce } \\
47 \text { states, excluding Alas }) \\
\text { \# Sum of lags } t=(0,-1,-2 \\
\text { bust standard errors in pa }\end{array}$ & $\begin{array}{l}\text { vel } \\
\text { awaii, and } \mathrm{R} \\
\text { eses }\end{array}$ & sland. & & \\
\hline
\end{tabular}


Table 3b: Pooled Time Series regression of variance of ROE of banks in a state on the shock to the distribution to bank ROE\#

$$
\operatorname{Var}\left(\mathrm{ROE}_{\mathrm{jt}}\right)=\mathrm{a}+\mathrm{b}\left(\text { shock }_{\mathrm{j} t}\right)
$$

Without controls With controls Without control With controls (state \& time) (state \& time)

\begin{tabular}{|c|c|c|c|c|}
\hline Intercept & $\begin{array}{l}0.024 \\
(0.001)^{* *}\end{array}$ & $\begin{array}{c}5.64 \mathrm{e}-3 \\
(4.67 \mathrm{e}-3)\end{array}$ & $\begin{array}{c}5.97 \mathrm{e}-03 \\
(2.28 \mathrm{E}-03)^{*}\end{array}$ & $\begin{array}{l}-0.020 \\
(0.007)^{*}\end{array}$ \\
\hline $\begin{array}{l}\text { Square of state shock\#\# } \\
\sum\left(\varepsilon_{\mathrm{jt}}\right)^{2}\end{array}$ & $\begin{array}{l}3.456 \\
(0.346)^{* *}\end{array}$ & $\begin{array}{l}2.898 \\
(0.299)^{* *}\end{array}$ & & \\
\hline 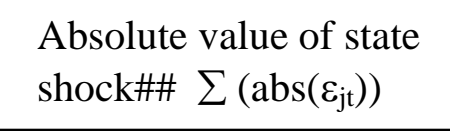 & & & $\begin{array}{l}1.129 \\
(0.131)^{* *}\end{array}$ & $\begin{array}{l}0.942 . \\
(0.156)^{* *}\end{array}$ \\
\hline $\begin{array}{l}\mathrm{R}^{2} \\
\text { N } 3948\end{array}$ & 0.15 & 0.412 & 0.172 & 0.399 \\
\hline \multicolumn{5}{|c|}{$\begin{array}{l}\text { ** significant at the } 1 \text { percent level } \\
\text { * significant at the } 5 \text { percent level } \\
\text { \# } 47 \text { states, excluding Alaska, Hawaii, and Rode Island. } \\
\text { \#\# Sum of lags } t=(0,-1,-2,-3) \\
\text { robust standard errors in parentheses }\end{array}$} \\
\hline
\end{tabular}


Table 4a: Variance Decompositions for Variance of State ROA

\begin{tabular}{l|cccc} 
Period & $\operatorname{var}\left(\mathrm{ROA}_{\mathrm{j}}\right)$ & $\left.\mathrm{abs}()_{\mathrm{j}}\right)$ & $\operatorname{var}\left(\mathrm{ROA}_{\mathrm{j}}\right)$ & $\left(\mathrm{J}_{\mathrm{j}}\right)^{2}$ \\
\hline 1 & 93.6 & 6.4 & 93.7 & 6.3 \\
2 & 91.5 & 8.5 & 92.0 & 8.0 \\
3 & 91.4 & 8.6 & 92.1 & 7.9 \\
4 & 91.4 & 8.6 & 92.1 & 7.9 \\
5 & 92.0 & 8.0 & 93.0 & 7.0 \\
6 & 91.4 & 8.6 & 92.7 & 7.3 \\
7 & 91.4 & 8.6 & 92.8 & 7.2 \\
8 & 91.4 & 8.6 & 92.8 & 7.2 \\
9 & 91.5 & 8.5 & 93.1 & 6.9 \\
10 & 91.4 & 8.6 & 93.0 & 7.0 \\
11 & 91.4 & 8.6 & 93.1 & 6.9 \\
12 & 91.4 & 8.6 & 93.1 & 6.9
\end{tabular}

(based on vector autoregression using variance of state ROA and state shock--4 lags)

Table 4b: Variance Decompositions for Variance of States' ROE

\begin{tabular}{l|cccc} 
Period & $\operatorname{var}\left(\mathrm{ROE}_{\mathrm{j}}\right)$ & $\left.\mathrm{abs}()_{\mathrm{j}}\right)$ & $\operatorname{var}\left(\mathrm{ROE}_{\mathrm{j}}\right)$ & $\left(\mathrm{J}_{\mathrm{j}}\right)^{2}$ \\
\hline 1 & 92.6 & 7.4 & 91.9 & 8.1 \\
2 & 90.1 & 9.9 & 90.4 & 9.6 \\
3 & 89.5 & 10.5 & 89.8 & 10.2 \\
4 & 89.1 & 10.9 & 89.6 & 10.4 \\
5 & 90.1 & 9.9 & 91.3 & 8.7 \\
6 & 89.6 & 10.4 & 91.2 & 8.8 \\
7 & 89.4 & 10.6 & 91.3 & 8.7 \\
8 & 89.3 & 10.7 & 91.3 & 8.7 \\
9 & 89.5 & 10.5 & 91.6 & 8.4 \\
10 & 89.3 & 10.7 & 91.7 & 8.3 \\
11 & 89.3 & 10.7 & 91.7 & 8.3 \\
12 & 89.3 & 10.7 & 91.7 & 8.3
\end{tabular}

(based on vector autoregression using variance of state ROE and state shock--4 lags) 
Figure 1a

Median, 25th and 75th Percentiles

(ROA)

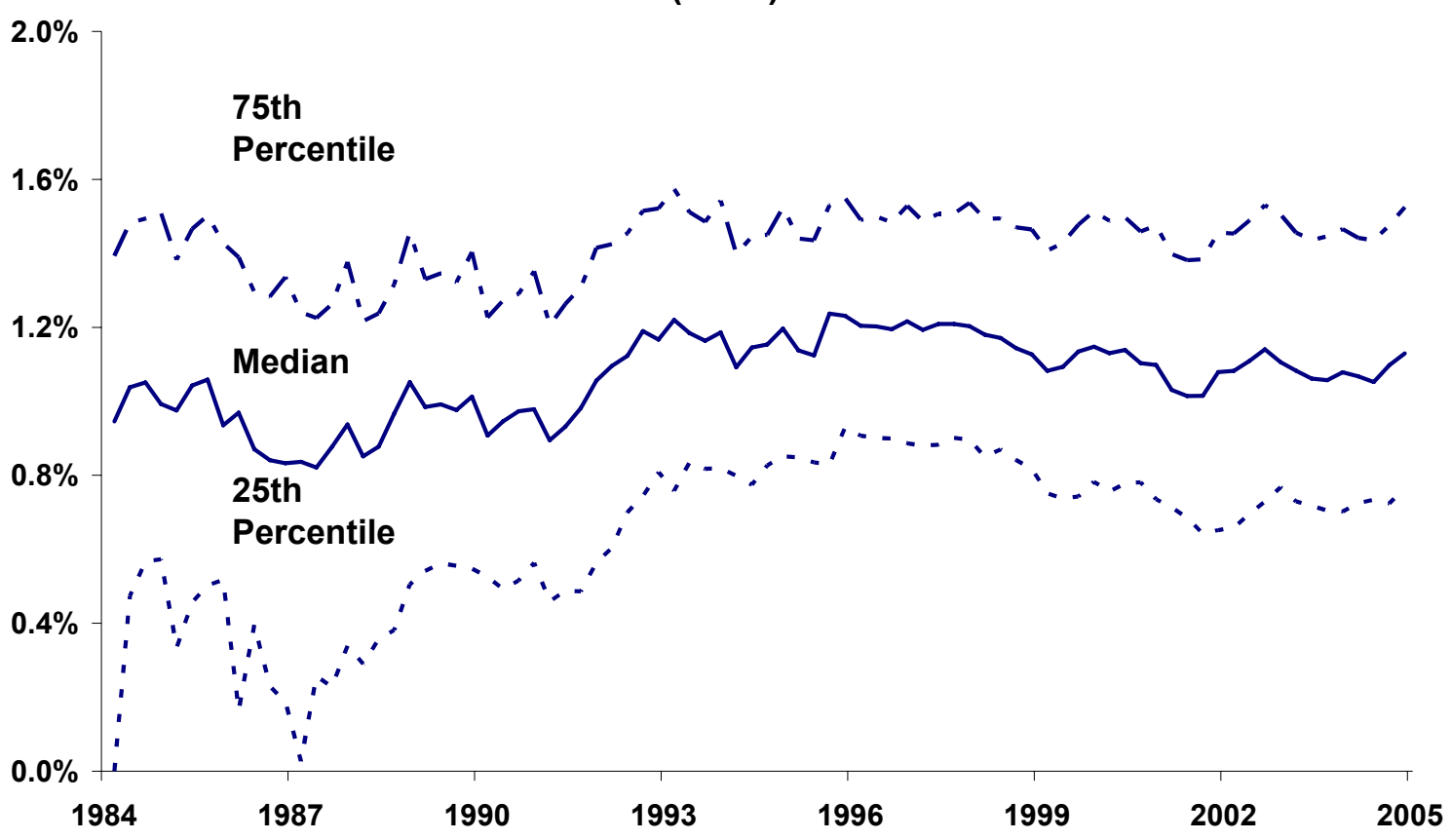

Figure 1b

Median, 25th and 75th Percentiles

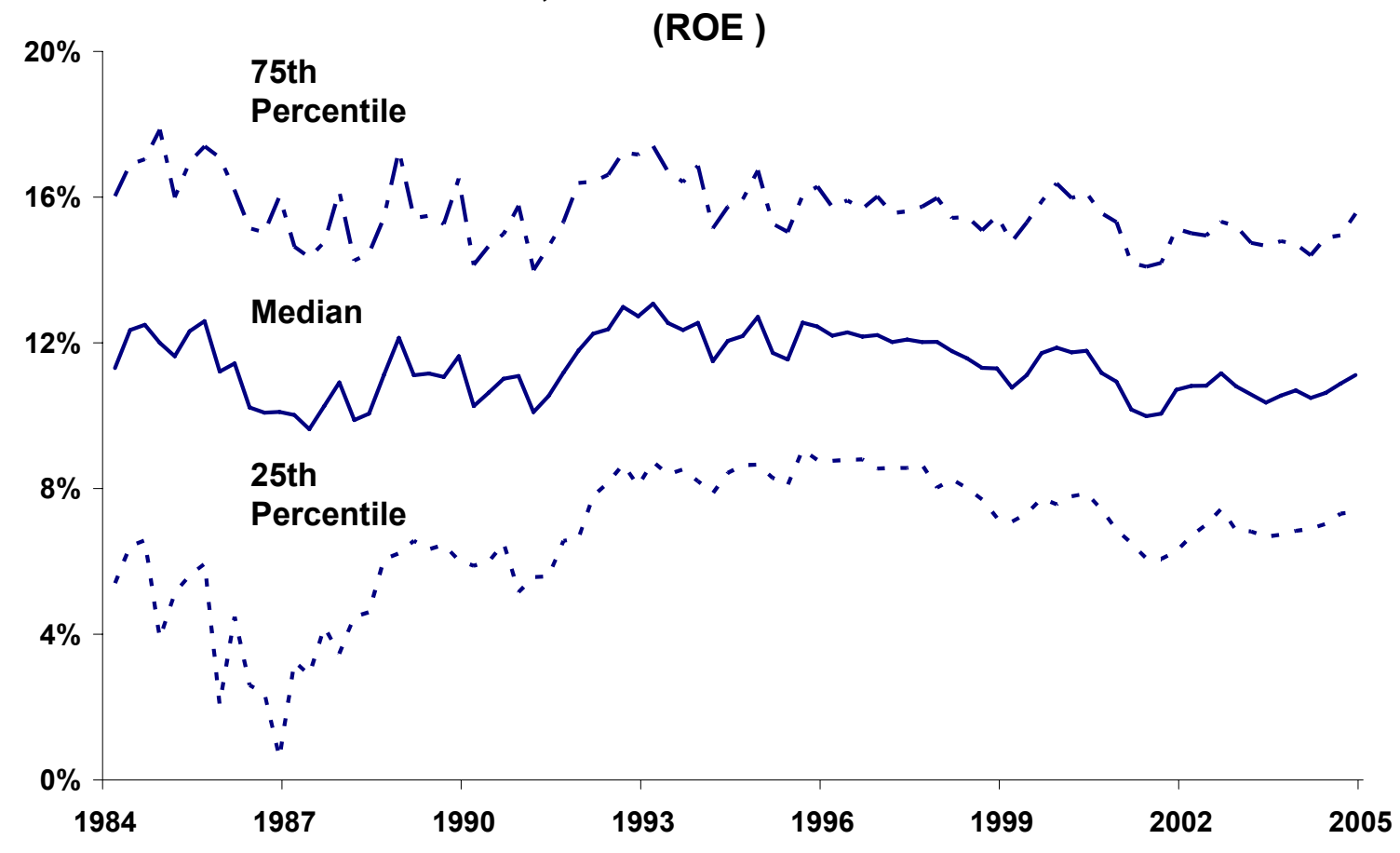


Figure 2a

Estimated State Component for Western Region

(ROA)

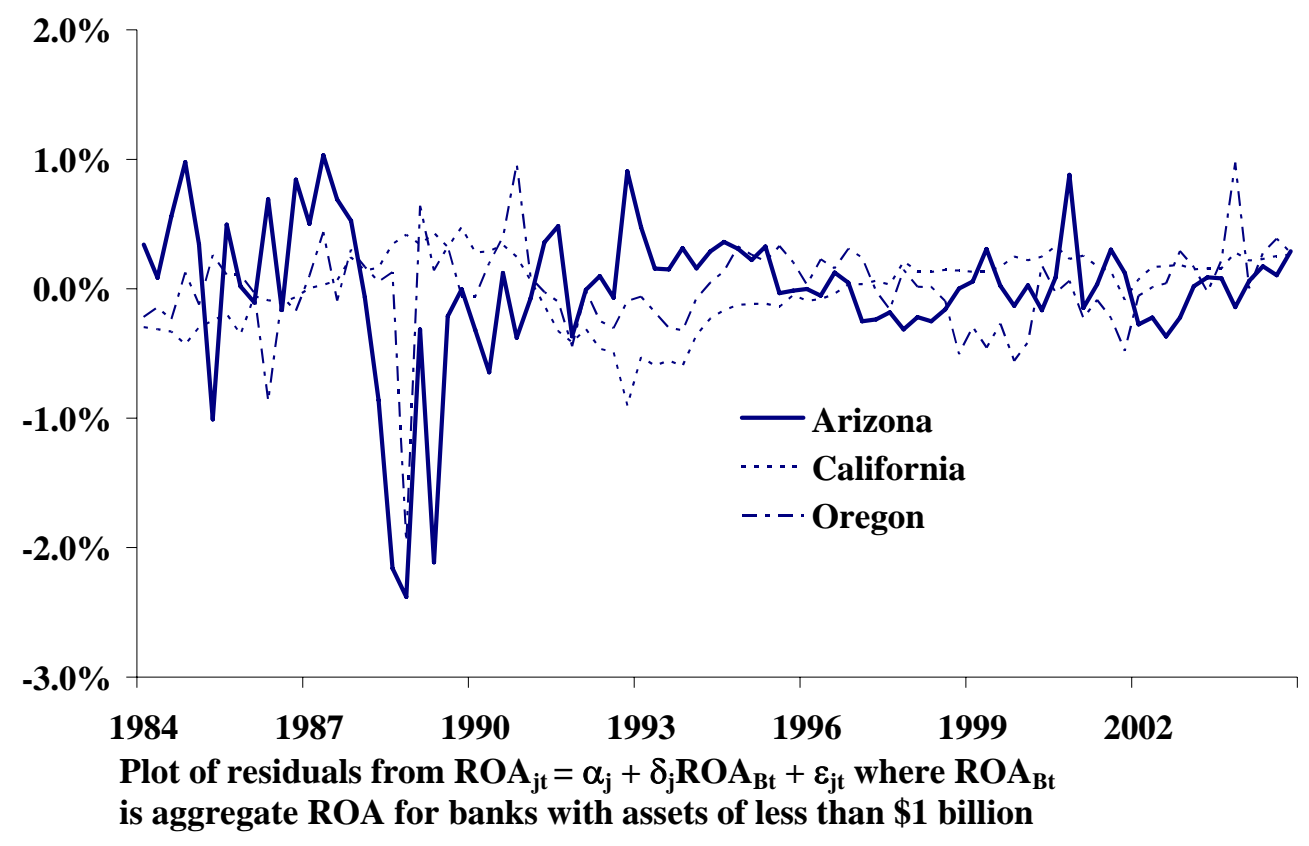

Figure 2b

Estimated State Component for Western Region

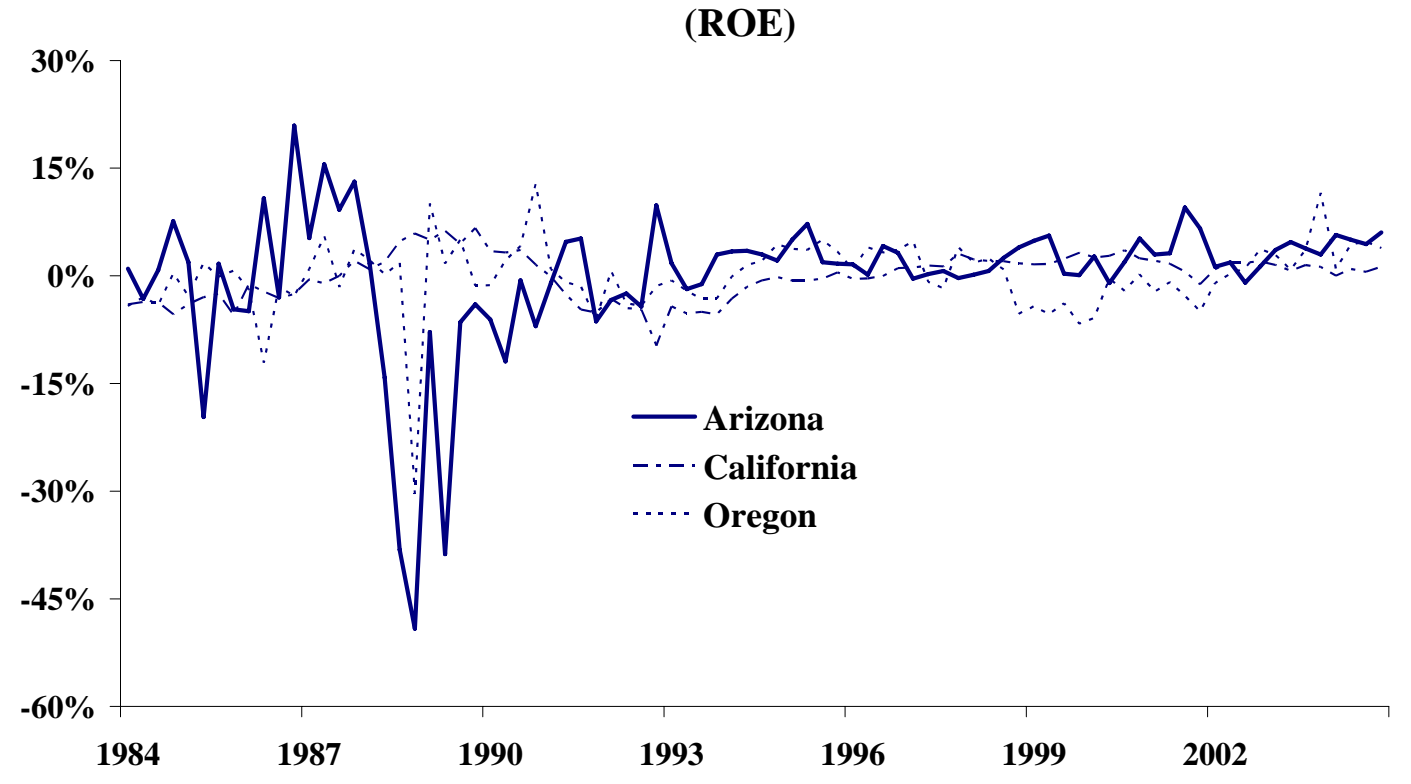

Plot of residuals from $R E_{j t}=\alpha_{j}+\delta_{j} R E_{B t}+\varepsilon_{j t}$ where $R E_{B t}$ is aggregate ROE for banks with assets of less than $\$ 1$ billion 
Figure 3a

Distributions of Responses of Individual Community

Banks' ROA to National and State Components

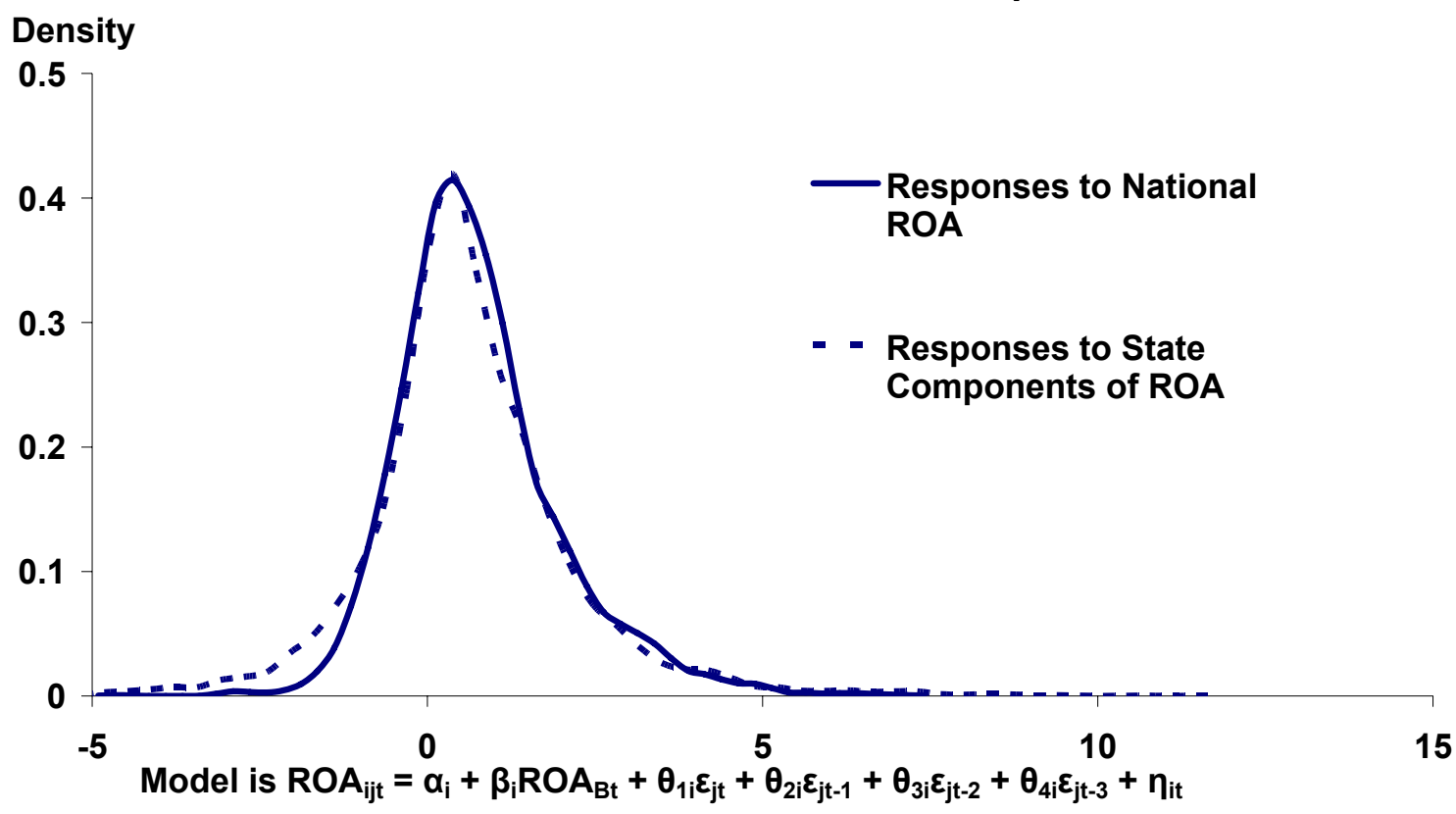

Figure 3b

Distributions of Responses of Individual Community Banks' ROE to National and State Components

Density

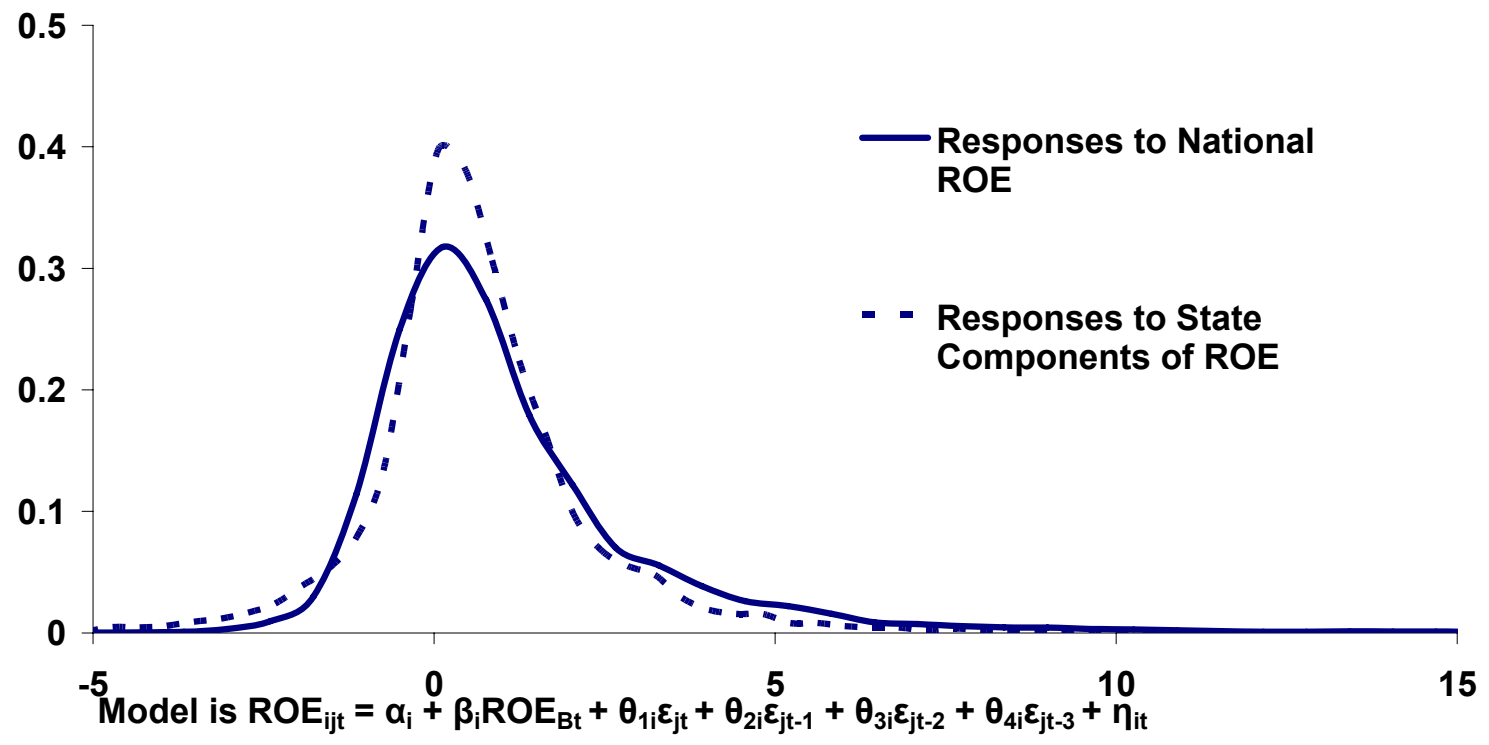


Figure 4a

Impulse Response of $\operatorname{var}\left(\operatorname{ROA}_{j}\right)$ to $\operatorname{abs}\left(\varepsilon_{j}\right)$

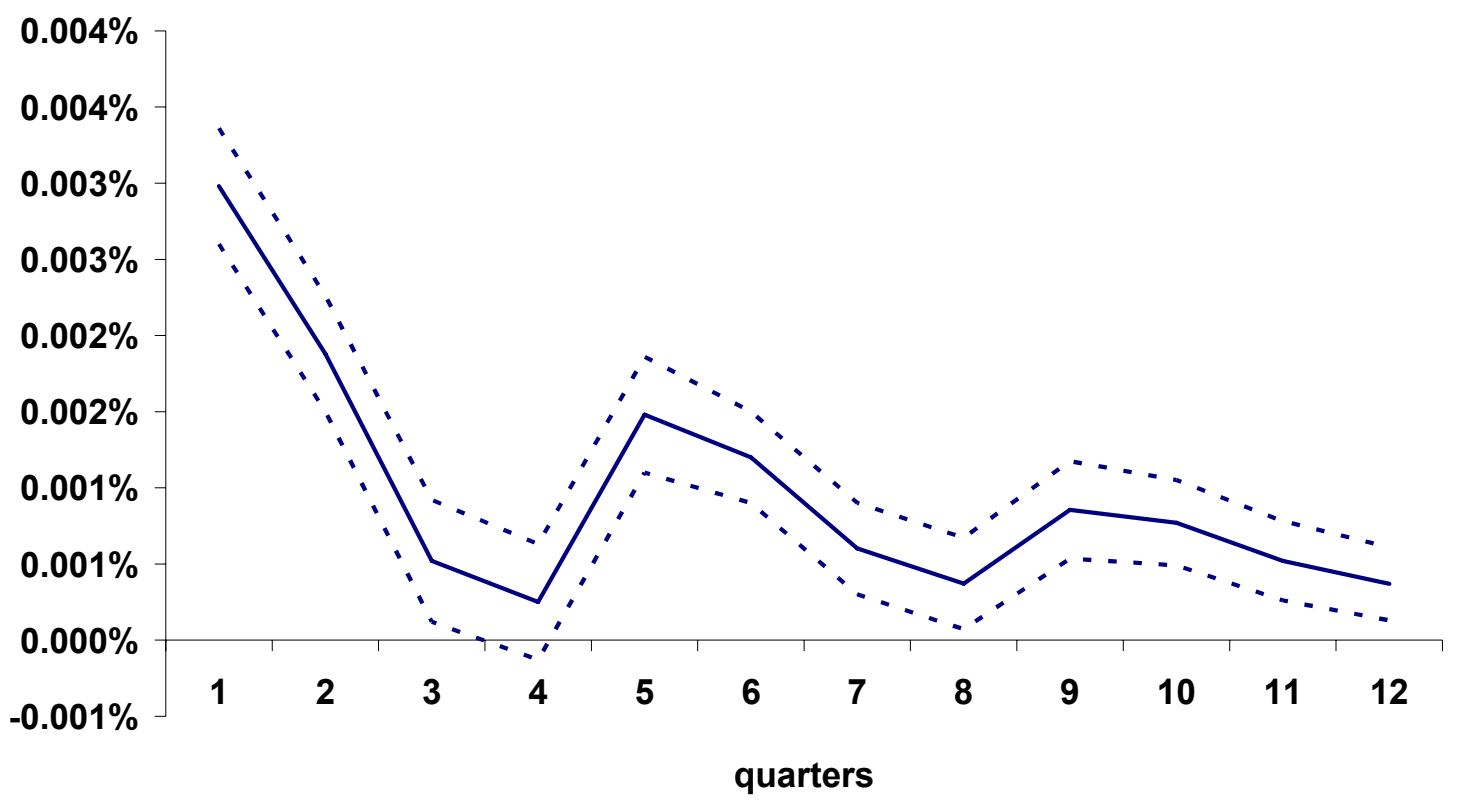

Figure 4b

Impulse Response of $\operatorname{var}(\mathrm{ROEj})$ to abs( $(\varepsilon j)$

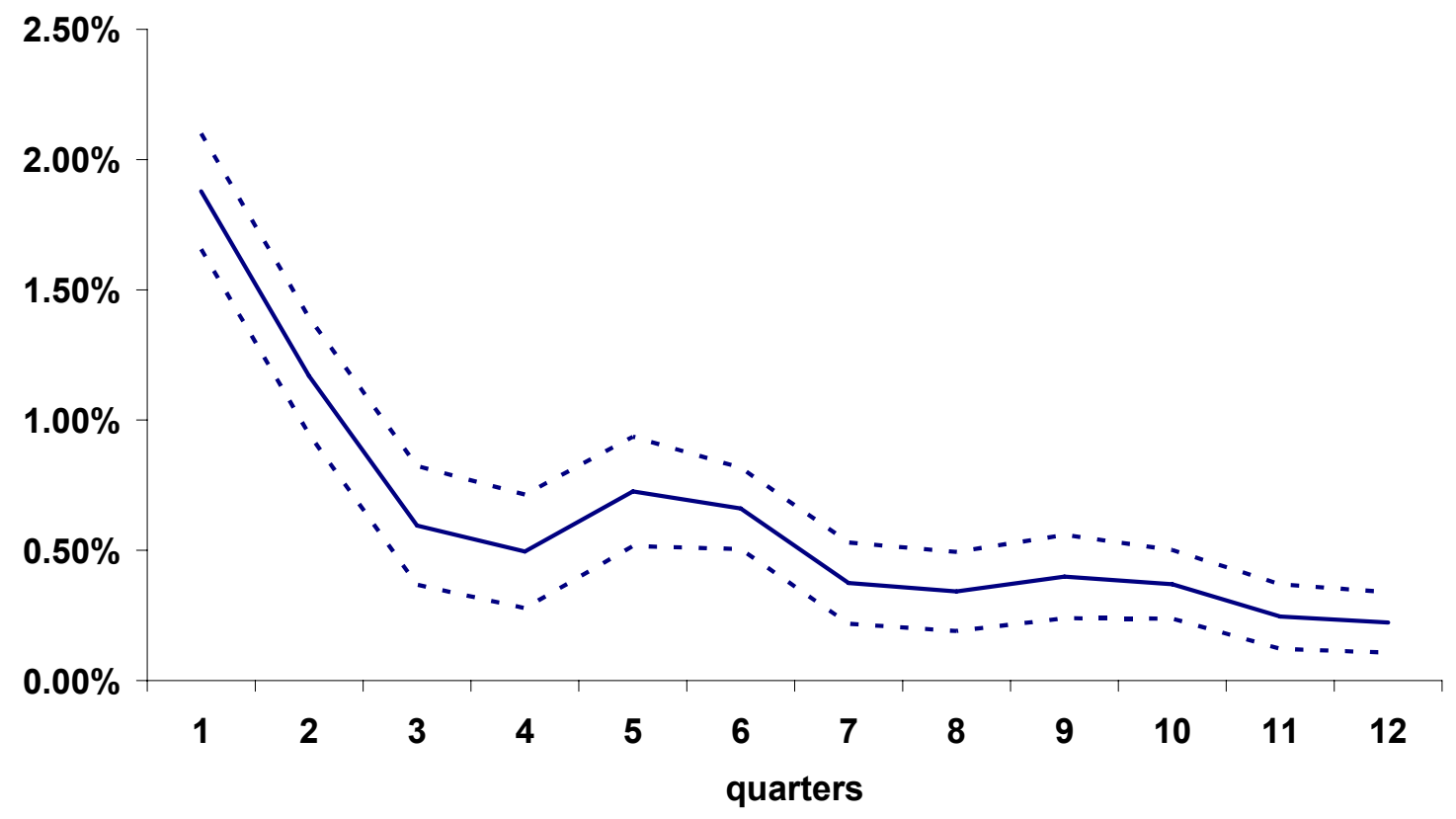


Figure 5a

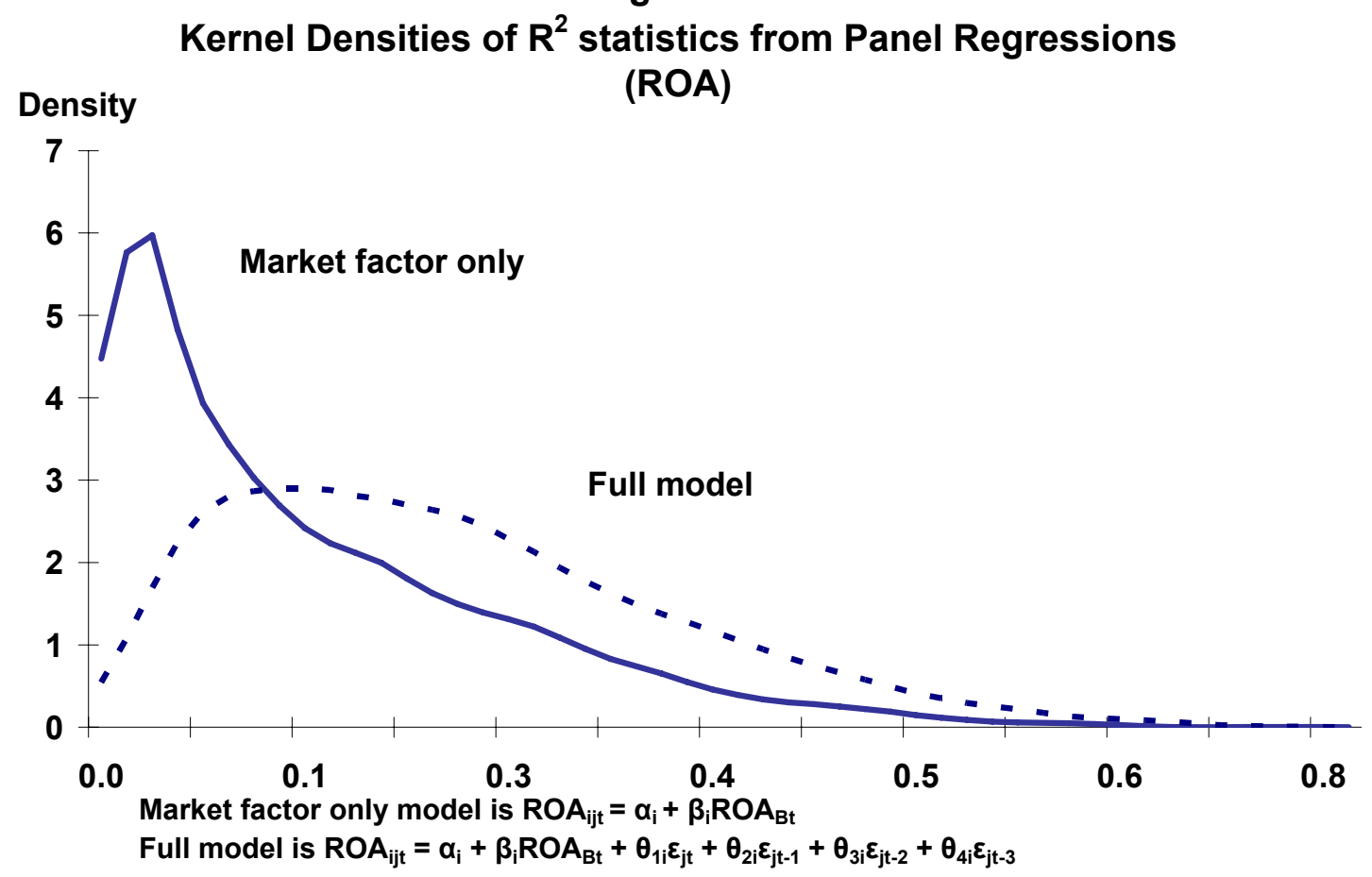

Figure 5b

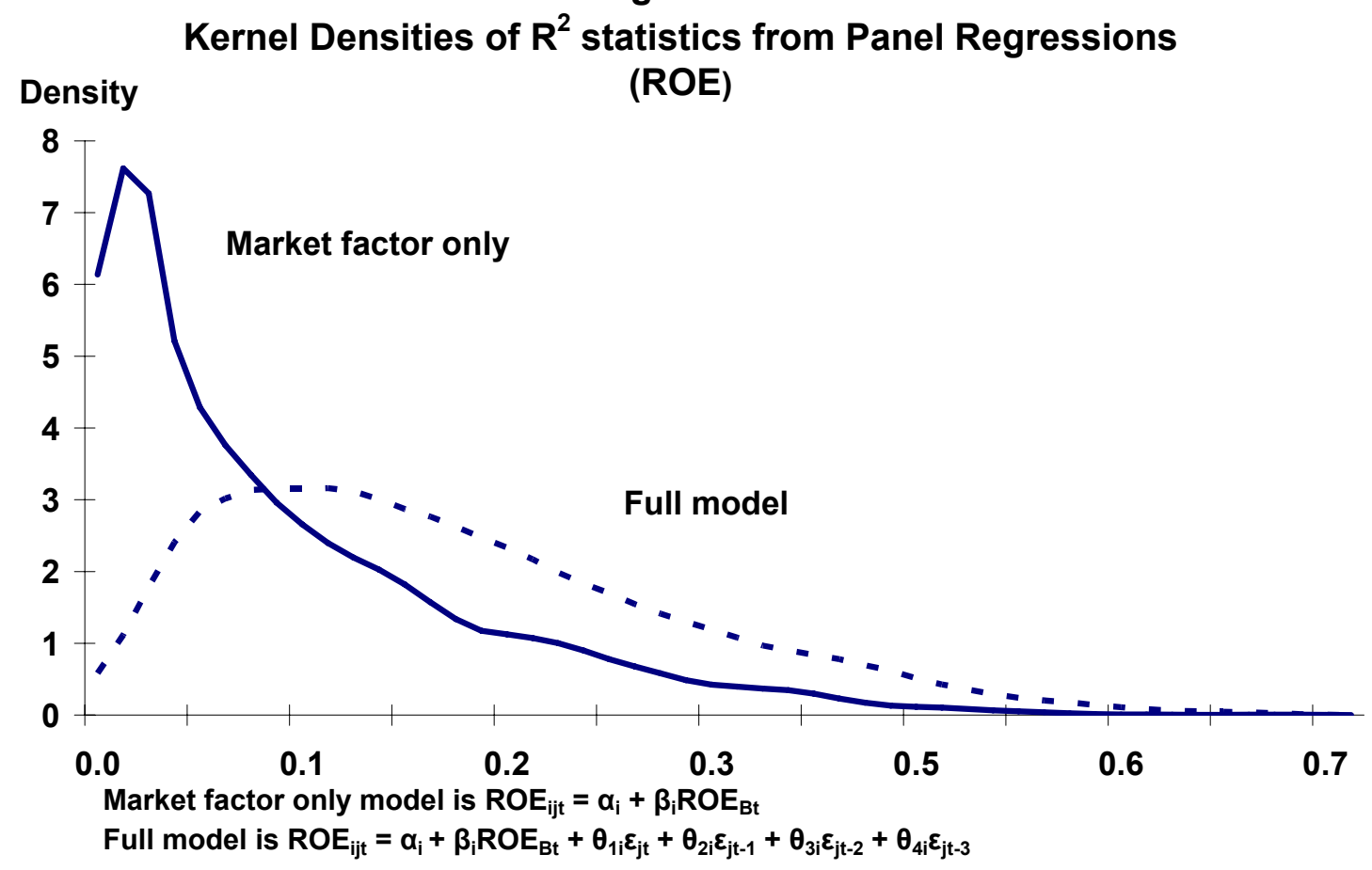

